\title{
EDUCAČÃO AMBIENTAL: UMA EXPERIÊNCIA COM RESÍDUOS SÓLIDOS DOMICILIARES
}

\author{
Anny Kariny Feitosa ${ }^{1}$ \\ Júlia Elisabete Barden² \\ Odorico Konrad ${ }^{3}$
}

Resumo: Este artigo tem por objetivo apresentar uma experiência de caráter prático efetiva, em uma Instituição de Ensino Superior no Ceará, a respeito da gestão de resíduos sólidos domiciliares, contribuindo para a disseminação do método da análise gravimétrica de resíduos sólidos como uma ferramenta de educação ambiental. Foi possível identificar o modo como os indivíduos tratam seus resíduos quanto à forma de acondicionamento; tipos de resíduos mais produzidos em determinados bairros; o expressivo desperdício de alimentos; o descarte de objetos que ainda possuíam vida útil. Da experiência vivenciada, ressalta-se que o método da análise gravimétrica de resíduos sólidos resultou eficiente como prática pedagógica de educação ambiental.

Palavras-chave: Resíduos Sólidos; Educação ambiental e sanitária; Sustentabilidade.

${ }^{1}$ Centro Universitário Univates. E-mail: akfeitosa@hotmail.com.

${ }^{2}$ Centro Universitário Univates. E-mail: jbarden@univates.br. 


\section{Introdução}

A análise gravimétrica de Resíduos Sólidos Urbanos (RSU) é uma importante ferramenta para avaliar as estratégias de gestão na tomada de decisão mais acertada a respeito da minimização de resíduos na fonte, reciclagem, reutilização, tratamento e disposição final. A literatura científica revela sua contribuição a partir da influência das características e padrões dos resíduos para o planejamento do sistema de gerenciamento e gestão em um município, subsidiando a otimização do processo de coleta, adequação da gestão de recursos humanos, bem como avaliação da necessidade de infraestrutura (GARDUÑO-PALOMINO et al., 2012; MEDEIROS; PAZ; MORAIS JUNIOR, 2015).

No âmbito da Educação Ambiental, a análise gravimétrica de resíduos sólidos se potencializa como prática educativa capaz de estimular a conscientização ambiental. A experiência apresenta um olhar mais holístico no que diz respeito à pesquisa da análise das quantidades e tipologias dos resíduos domiciliares gerados e descartados, amparado pela educação ambiental, que de acordo com a Política Nacional de Educação Ambiental, possui como objetivos fundamentais: "o desenvolvimento de uma compreensão integrada do meio ambiente em suas múltiplas e complexas relações, envolvendo aspectos ecológicos, psicológicos, legais, políticos, sociais, econômicos, científicos, culturais e éticos" (BRASIL, 1999, p.2).

Saugo e Fernandes (2013, p.65), em estudo relatando a didática voltada para a sustentabilidade, afirmaram haver melhora "na consciência dos estudantes e maior apropriação e aplicação dos conhecimentos de práticas direcionadas à sustentabilidade". Ademais, Santos et al. (2016, p.58) destacaram "que as ações educativas ambientais necessitam de aspectos práticos para tornarem-se significativas e ativas para os educandos e a comunidade escolar".

Diante do exposto, este artigo tem por objetivo apresentar uma experiência de caráter prático efetiva, em uma Instituição de Ensino Superior no Ceará, a respeito da gestão de resíduos sólidos domiciliares, contribuindo para a disseminação do método da análise gravimétrica de resíduos sólidos como uma ferramenta de educação ambiental.

\section{Relato}

A experiência aqui relatada aconteceu no âmbito de um projeto de análise gravimétrica de resíduos sólidos domiciliares, realizado no município de Juazeiro do Norte, durante o ano 2016. Para o desenvolvimento das atividades, participaram alunos vinculados ao curso de Engenharia Ambiental de uma Instituição de Ensino Superior, no Estado do Ceará, e de um Centro Universitário, localizado em Lajeado, RS.

Inicialmente, realizou-se a coleta porta a porta de resíduos sólidos domiciliares, a partir do cadastro prévio de 53 domicílios, distribuídos em 6 bairros da cidade de Juazeiro do Norte, no Estado do Ceará. Cada bairro 
selecionado representava um estrato socioeconômico, conforme a classificação da ABEP (2012). A seleção dos domicílios ocorreu por amostragem aleatória simples (GIL, 2008).

O processo de coleta porta-a-porta foi recolher, nos domicílios cadastrados, os resíduos produzidos diariamente por seus habitantes, durante duas semanas, nos meses de abril, junho e agosto de 2016. Os resíduos foram acondicionados em tambores com capacidade de 120 litros e transportados para posterior análise.

Durante a coleta, foram vivenciadas inúmeras situações, das quais se destacam: o resíduo descartado sem uma prévia separação, acondicionados em uma mesma sacola ou em caixas de papelão e baldes plásticos abertos. Com relação ao tempo dispendido durante a coleta, todo o percurso durava aproximadamente 2 horas.

Outro fator elencado foi a dificuldade encontrada por alguns domiciliados em participar da entrega dos resíduos durante toda a semana de campanha, quando eventualmente necessitavam se ausentar de suas casas no horário da coleta. Contudo, salienta-se que foram casos esporádicos e não interferiram no desenvolvimento das atividades. De um modo geral, foi perceptível a atenção dos cadastrados em contribuir com a pesquisa.

O Processo de triagem (Figura 1) foi realizado no período vespertino, em uma área coberta, contendo mesa, baldes e balanças para o manuseio, pesagem e volumagem dos resíduos (Figura 2). Os resíduos foram analisados separadamente por bairro de origem.

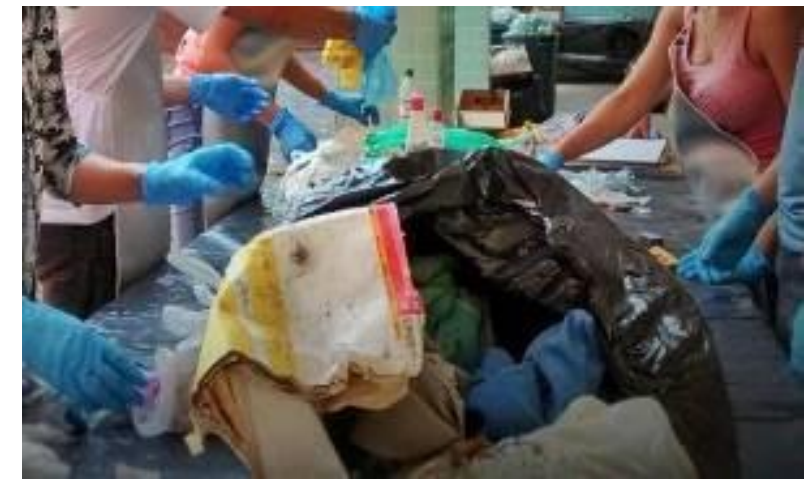

Figura 1: Processo de triagem de resíduos. Fonte: pesquisa aplicada.

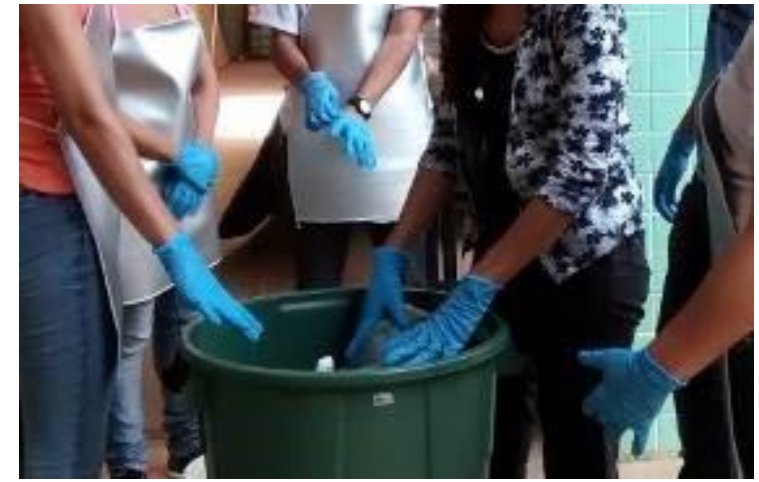

Figura 2: Volumagem de resíduos. Fonte: pesquisa aplicada.

Principalmente no processo de triagem, os alunos participantes da atividade sentiram algumas dificuldades, seja devido ao esforço físico, pela necessidade de lidar com o odor dos resíduos descartados, ou mesmo pela inexperiência com a atuação prática de separar os resíduos em cada categoria, conforme pode ser observado na fala de um participante que afirma "eu sabia que seria algo difícil, por nunca ter trabalhado dessa forma com resíduos sólidos. O trabalho é árduo e muito cansativo." Em muitos dos dias, o trabalho Revbea, São Paulo, V. 12, № 2: 178-183, 2017. 
se prolongou até o início da noite, devido ao volume de resíduos gerados e coletados, bem como pelas dificuldades iniciais com a atividade no início "as triagens demoravam muito tempo". Durante a segunda semana de campanha, a equipe conseguiu se organizar e promover o processo de triagem de forma mais rápida, principalmente pelo fato de já estar familiarizada com os tipos de resíduos mais comumente encontrados.

Ainda no processo de triagem, pode-se realizar um diagnóstico de como os indivíduos manuseiam e destinam seus resíduos. Foram observadas: formas de acondicionamento, tipos e quantidades de resíduos produzidos por cada bairro; o desperdício de alimentos; e o descarte de objetos que ainda possuíam vida útil, que poderiam ter sido doados ao em vez de ser descartados. Aponta-se como necessidade uma mudança cultural em termos de consumo, desperdício e descarte de resíduos (MEDEIROS et al., 2015).

Ademais, nesta etapa das atividades, os alunos identificaram que havia diferenças no modo de acondicionamento, de acordo com o bairro de origem dos resíduos. Evidenciou-se que os bairros de estrato socioeconômico mais baixos, em geral, dispõem seus resíduos acomodados em um mesmo recipiente. Usualmente, são sacolas plásticas de supermercado, em que são agrupados todos os resíduos gerados no domicílio, inclusive contendo resíduos especiais, que deveriam ter um destino ambientalmente adequado. Em alguns casos, foi possível encontrar sacolas separadas com papel sanitário e fraudas descartáveis. Porém, a prática de acondicionar juntos os resíduos secos e úmidos prevaleceu nestes bairros.

Ao passo em que, em estratos socioeconômicos mais elevados, foi identificado o uso de sacolas distintas para resíduos orgânicos, resíduos secos e papel sanitário, na maioria dos domicílios. Nesse caso, demostra-se um conhecimento prévio e preocupação por parte do domiciliado acerca do manuseio e destinação de seus resíduos. Foi possível observar, ainda, a partir das características dos resíduos coletados que os tipos de embalagem, marcas de produtos consumidos, sua composição e limpeza, variavam em função do bairro gerador, devido ao estrato socioeconômico.

Após sua análise e classificação, os resíduos foram agrupados nas categorias: Recicláveis, Orgânicos e Rejeitos, para estimar o volume e massa específica produzida de cada categoria. A partir desses resultados, pode-se futuramente dimensionar as estruturas necessárias para armazenamento de resíduos em uma proposta de coleta seletiva nos bairros da cidade. Por fim, procedeu-se com o descarte dos resíduos, ocasião em que os resíduos orgânicos e o rejeito foram destinados à coleta pública municipal e o material com potencial reciclável foi destinado para catadores atuantes no município.

\section{Discussão}

O desenvolvimento das atividades permitiu destacar que há muitas lacunas na gestão de resíduos sólidos domiciliares, a maioria delas relacionadas com a necessidade de implementação de ações educativas 
ambientais e sanitárias. É importante que a população seja envolvida e passe a contribuir efetivamente com o saneamento básico da cidade, despertando no sentido da melhor qualidade de vida e adoção de novas práticas de consumo e descarte na lógica da sustentabilidade (FARIAS, 2010).

Neste sentido, a educação ambiental se configura como "principal instrumento de transformação, sendo fundamental para o desenvolvimento de uma consciência crítica em relação ao meio ambiente, gerando comprometimento e responsabilidade da população nas ações de saneamento e saúde" (SOARES et al., 2007, p.1)

Ao longo das atividades realizadas, percebeu-se engajamento da comunidade participante, que manifestava interesse em destinar os resíduos para o "Projeto do lixo", como ficou popularmente conhecido. A população ficou curiosa em ver o trabalho acontecendo. As pessoas nas ruas perguntavam "pra que recolhem o lixo dessas casas?", "Porque não pegam lixo da minha casa também?". Outros procuravam conhecer e saber do que se tratavam as atividades. Houve curiosidade também na Instituição de Ensino, por parte de discentes e docentes do curso de Engenharia Ambiental, não participantes do projeto, em que surgiram perguntas sobre a natureza e os objetivos das atividades. Neste sentido, Almeida et al. (2004, p.122) afirmam que "a Educação Ambiental nas escolas deve sensibilizar o professor e o aluno para que construam coletivamente o conhecimento por meio de estratégias pedagógicas de mudança de mentalidade".

A experiência colabora, ainda, com os futuros profissionais da Engenharia Ambiental, que atuaram nas atividades com o preparo científico atrelado ao conhecimento adquirido a partir do convívio com a comunidade assistida, conforme relata um dos participantes "é muito gratificante, como futuro Engenheiro Ambiental poder conhecer de fato como são os trabalhos com resíduos em todos os níveis, desde a população que os descarta, o gari e catador que os coletam e separam, até o Engenheiro que realizará o Plano de Gerenciamento Municipal desses resíduos". Salienta-se que a ação desenvolvida utilizando a análise gravimétrica dos resíduos sólidos propiciou um olhar diferenciado para os problemas ambientais causados pela geração, descarte e disposição dos resíduos no município em estudo.

\section{Considerações finais}

A proposta de introduzir o método de análise gravimétrica de resíduos como prática pedagógica de educação ambiental mostrou-se enriquecedora para a formação acadêmica dos alunos, que tiveram a oportunidade de participar de discussões e vivências, capazes de contribuir significativamente com o desenvolvimento de suas habilidades profissionais (FEITOSA et al., 2016), proporcionando o despertar para o cuidado com o meio ambiente, a partir da reflexão sobre a quantidade, tipos de resíduos gerados e a necessidade da adoção de novos hábitos que contribuam para a sustentabilidade. 
Além disso, possibilitou a visualização das deficiências no serviço público da gestão de resíduos voltada para a população, em que se cumpre apenas uma função restrita de coletar e dispor os resíduos, em uma periodicidade que varia de bairro para bairro, mas que não educa ambientalmente a população sobre a importância de reduzir a geração dos resíduos, ou ainda sobre o seu manuseio e descarte adequados.

\section{Referências}

ABEP - Associação Brasileira de Empresas de Pesquisa. Critério de Classificação Econômica Brasil - 2012. Disponível em: $<$ http://www.abep.org/criterio-brasil> Acesso em: 25 jan. 2016.

ALMEIDA, L.F.R.; BICUDO, L.R.H.; BORGES, G.L.A. Ciência \& Educação, v. 10, n. 1, p. 121-132, 2004.

BRASIL. Lei Federal no 9.795, de 27 de abril de 1999. Dispõe sobre a educação ambiental, institui a Política Nacional de Educação Ambiental e dá outras providências. Diário oficial da União, Brasília, 28 abr. 1999.

FARIAS, A.M.B. Interações comunicacionais na educação ambiental: um estudo da apropriação da política pública da coleta seletiva por moradoras/consumidoras em Lajeado - RS. Mestrado em Ambiente e Desenvolvimento (Dissertação). Univates: Lajeado, 2010. 156 p.

FEITOSA, A.K.; BARDEN, J.E.; KONRAD, O.; HASAN, C.; DAMASCENO, M.M.S.; SILVA, A.M.M.; PALACIO, O.D. ; MARQUES JUNIOR, F.A.F. ; BARBOSA, J.C. ; LIMA, M.R.P. Experiências de uma oficina de resíduos sólidos. Revista Educação Ambiental em Ação, v. 15, n.58, p. 1-6, 2016.

GARDUÑO-PALOMINO, K.; OJEDA-BENITEZ, S.; ARMIJO DE VEGA, C. Caracterización de residuos sólidos generados por el sector comercial de Mexicali, B.C. Rev. Int. Contam. Ambient, México, v.28, supl.1, p.21-27, 2012. GIL, A.C. Métodos e técnicas de pesquisa social. 6 ed. Atlas Novo: São Paulo, 2008.

MEDEIROS, J.E.S.F.; PAZ, A.R.; MORAIS JUNIOR, J. A. Análise da evolução e estimativa futura da massa coletada de resíduos sólidos domiciliares no município de João Pessoa e relação com outros indicadores de consumo. Eng. Sanit. Ambient., Rio de Janeiro, v. 20, n. 1, p. 119-130, Mar. 2015.

SANTOS, V.S.; SCHMITT, J.L.; ROSA, M.D. A educação ambiental como potencial para o gerenciamento de resíduos sólidos escolares: o caso da emef boa saúde, Novo Hamburgo (RS). Revbea, S.Paulo, v.11, n.5, p.53-66, 2016.

SAUGO, A.; FERNANDES, L. C.. Ensino e extensão: relato de uma experiência didática voltada para a sustentabilidade. Revista de Arquitetura da IMED, v. 2, n.1, p. 56-66, 2013.

SOARES, L. G. C.; SALGUEIRO, A. A.; GAZINEU, M. H. P. Educação Ambiental aplicada aos resíduos sólidos na cidade de Olinda, Pernambuco um estudo de caso. Revista Ciências e Tecnologia, v 1, n. 1, 2007. 